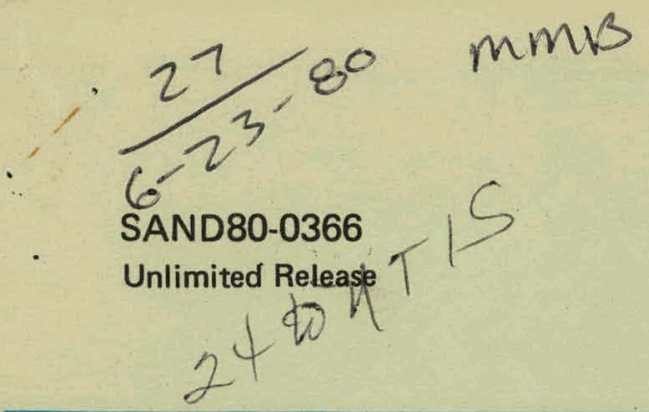

\title{
Observations on the Use of the Consequence Model CRAC for Small Nonreactor Atmospheric Releases
}

David M. Ericson, Jr.

Prepared by Sandia Laboratories, Albuquerque, New Mexico 87185 and Livermore, California 94550 for the United States Department of Energy under Contract DE-AC04-76DP00789

Printed May 1980 


\section{DISCLAIMER}

This report was prepared as an account of work sponsored by an agency of the United States Government. Neither the United States Government nor any agency Thereof, nor any of their employees, makes any warranty, express or implied, or assumes any legal liability or responsibility for the accuracy, completeness, or usefulness of any information, apparatus, product, or process disclosed, or represents that its use would not infringe privately owned rights. Reference herein to any specific commercial product, process, or service by trade name, trademark, manufacturer, or otherwise does not necessarily constitute or imply its endorsement, recommendation, or favoring by the United States Government or any agency thereof. The views and opinions of authors expressed herein do not necessarily state or reflect those of the United States Government or any agency thereof. 


\section{DISCLAIMER}

Portions of this document may be illegible in electronic image products. Images are produced from the best available original document. 
Issued by Sandia National Laboratories, operated for the United States Department of Energy by Sandia Corporation.

\section{NOTICE}

This report was prepared as an account of work sponsored by an agency of the United States Government. Neither the United States Government nor any agency thereof, or any of their employees, makes any warranty, expressed or implied, or assumes any legal liability or responsibility for any third party's use, or the results of such use, of any information, apparatus, product or process disclosed in this report, or represents that its use by such third party would not infringe privately owned rights.

Printed in the United State of America Ávailable from

National Technical Information Service U. S. Department of Commerce 528 Port Royal Road Springfield, VA 22161 Price: Printed Copy $\$ 4.50 ;$ Microfiche $\$ 3.00$ 
SAND80-0366

Unlimited Release

Printed May 1980

OBSERVATIONS ON THE USE OF THE CONSEQUENCE MODEL

CRAC FOR SMALL NONREACTOR ATMOSPHERIC RELEASES

David M. Ericson, Jr.

Nuclear Facility Analysis Division 4414

Sandia National Laboratories, Albuquerque, NM 87185

\section{ABSTRACT}

The consequence model CRAC from the Reactor Safety Study recently has been applied to atmospheric releases of radioactive material from nonreactor sources. This study examines the effect of three model parameters, interval size, population distribution and plume thermal bouyancy, on the consequence estimates. Recommendations for the appropriate use of CRAC in such consequence studies are included.

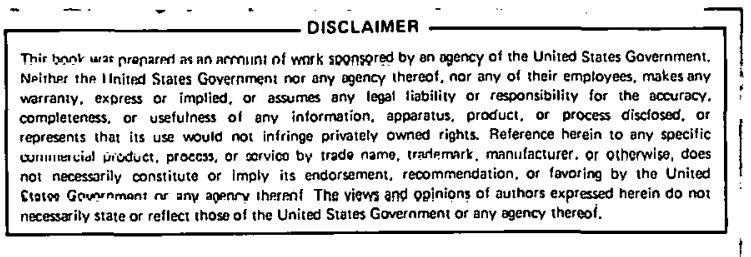


TABLE OF CONTENTS

Page

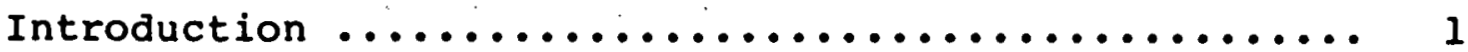

Significant Features of the CRAC Model ............ 2

Influence of Spatial Interval size .............. 3

Influence of Assumed Population Density .......... 5

Influence of Thermal Content of Plume ........... 8

Conclusions and Recommendations ................ 9

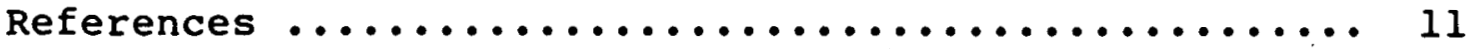


Table

Page

1 Normal Interval Radii for CRAC ........... 13

2 Modified Close-in Interval Radii for CRAC

Sensitivity study .................... 14

3 Normalized Consequence Estimates from

CRAC (Spatial Intervals Varied, Results

Normalized to Those at $0.06 \mathrm{~km}$ Spacing) .... 15

4 Assumed Population Distributions for

Consequence Estimates ................. 16

5 Mean CRAC LCF Estimates for a Release

from Spent Fuel ................... 17

Normalized Mean Consequence Estlmates Eur

Releases from Spent Fuel with Varying

Thermal Sources 


\section{Figures}

Figure

$\underline{\text { Page }}$

Cumulative Fraction of Latent Cancer Fatalities as Function of Distance from

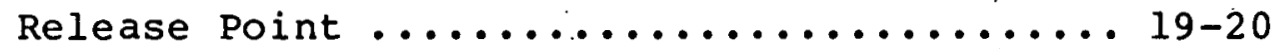




\section{ACKNOWLE DGEMENTS}

The author is indebted to his colleagues, D. C. Aldrich and J. M. Taylor, for many helpful discussions of consequence modelling and their suggestions of questions requiring resolution. 
Introduction

As part of the Reactor safety study, a consequence model, CRAC, was developed to examine the public consequences of accidental releases of radioactive material from nuclear power plants: ${ }^{1-3}$ since the development of the model, several studies have been conducted to examine the sensitivity of the model to factors such as plume rise, wind shear, rain, and population evacuation. 4-1l All of these studies were performed assuming one or more of the potentially large accidental releases from reactor sites. At the same time, CRAC has been used to examine the consequences of sabotage-caused releases from spent fuel 12,13 during transport. In the most recent study, the consequence estimates obtained with CRAC were compared with those obtained using METRAN, the consequence model developed for the Urban Study.13 In the course of this comparison it was apparent that the degree of agreement between the two consequence models was strongly influenced by the way CRAC was used, especially in regard to the size of the spatial intervals, the assumed population density and the thermal content of the released plume. Therefore, these factors were examined parametrically to establish their influence on consequence estimates. The results of these studies are reported here.*

\footnotetext{
${ }^{*}$ The computational results in the Urban study $^{13}$ reflect what we believe to be a judicious use of CRAC and the insights generated in this study.
} 
The CRAC model has been more fully described elsewhere ${ }^{1-3}$; however, it is appropriate to note here some of the features which bear upon the parameters mentioned above. CRAC operates basically on a radial computational mesh. The circular area is centered at the release point and divided into 16 segments each of $22-1 / 2^{\circ}$. Each segment has 34 radial intervals, the inner and outer radii of which can be specified by the analyst. The population distribution surrounding the site may be specified in several ways: (1) a uniform pupulation deneity can be ascribed to the entirc area, (2) the actual population in each discrete area can be specified, or (3) with slight code modification, a uniform population density can be specified within selected radial intervals. CRAC has provisions for including cloud rise due to thermal buoyancy, in which case the analyst specifies a heat rate which may be due to radioactive decay processes or sensible heat added by some other mechanism. The model a'sn has provisons for using either constant weather characteristics set by the analyst or actual hourly weather records from selected sites. In the usual mode of operation, releases are assumed to move radially outward in each of the $22-1 / 2^{\circ}$ segments for 91 different sequences of weather conditions sampled from a full year of data from a site. The results of these calculations are combined and reported as frequency distributions of consequence values. Statistics on those distributions, such as mean and standard deviations, as well as the distributions 
are also available in the code output. If a uniform population density is run, the mean will be for 91 calculations since each radial segment is identical. If the population distribution is fully specified (544 entries), then the mean will be computed from 1456 separate calculations $(16 \times 91=$ $1456)$.

\section{Influence of Spatial Interval size}

The normal CRAC radial intervals, shown in Table 1; were established to adequately reflect atmospheric concentrations from large reactor releases over a very large geographical area. Therefore, the interval lengths were set at $0.5 \mathrm{mile}$ out to a 5 mile radius, and gradually increased to 5 miles at a 20 mile radius. This provides more detail in close where conditions are changing fairly rapidly. Beyond the 85 mile radius the intervals become much larger.

When the initial consequence estimates were made for the Urban Study, 13 the decision was made to reduce the close-in intervals to $0.5 \mathrm{~km}$ in length based in part on the fact that the METRAN model uses a one square kilometer calculational grid with considerable internal detail. However, because of this detail and the fact that the dispersion calculation associated with METRAN has finer resolution, the question arose as to whether or not CRAC could or should be run with smallex intervals. To explore this question, calculations were made using nominal close in interval spacings of 1.0 , 
$0.8,0.5,0.25,0.12$, and $0.06 \mathrm{kilometer.*}$ The results are shown on Table 3. Several points should be noted about these results. The predictions of early fatalities (EF) and early morbidities (EM) both exhibit sensitivity to interval size with the EF showing the strongest dependence. This behavior is due to the fact that EF and EM are computed in terms of individual exposures, and because there are dose response thresholds involved. That is, as the interval size is reduced, the dose in the innermost intervals rises (CRAC assigns a single value, the average, to the entire interval) and therefore individual doses rise to levels sufficient to cause an effect. It is noteworthy that there is a point at which decreasing the interval size further has no significant effect. This is expected because once the average dose in an interval is above the level required for $100 \%$ effect, further increases will make no difference. The predicted latent cancer fatalities (LCF) are insensitive to the size of the spatial interval. This is also as expected since LCF are computed based upon the total population dose (person-rem). Therefore if the intervals are smaller, the dose may be higher but there are fewer people exposed so the product is essentially constant.

\footnotetext{
*Although the Martin and Tikvart fits for the Pasquill-Gifford (PG) curves are questionable within $1 / 2 \mathrm{~km}$ of the release point they were used in the initial calculations bccausc they are in CRAC. Subsequent calculations with other fits to the PG curves confirm the results reported here.
} 


\section{Influence of Assumed Population Density}

studies using CRAC are frequently conducted using uniform population densities. In fact, many analyses have been conducted assuming 38.5 persons per square kilometer (100 per square mile) which is a reasonable average figure for the continental United States. However, the recent applications of CRAC have been concerned with urban areas where thẹ population densities are many times greater. Unfortunately, there has been a tendency on the part of some observers to simply scale estimates from one population density to another. Such scaling can lead to erroneous and at times absurd results. These problems are illustrated in the following paragraphs.

At a population density of 38.5 persons $/ \mathrm{km}^{2}$, there are some 4.9 million people assumed to be in the $22-1 / 2^{\circ}$ sector extending out to $800 \mathrm{~km}$ downwind from the release point, certainly not an unreasonable number. 'Now if one simply scales the population density to 77000 persons $/ \mathrm{km}^{2}$. which is representative of a hyperurban area, then there would be 9.8 billion in the same area. Clearly, this has no relation to the real world.

An alternate view of the problems engendered by linear scaling may be achieved by examining.the consistency between the predicted number of LCFs and the individual radiation dose. One estimate for a particular release from spent fuel predicted $0.6 \mathrm{LCF}$ at a population density of 38.5 persons $/ \mathrm{km}^{2}$. Assuming a density of 77000 persons $/ \mathrm{km}^{2}$ and 1 inearly scaling, 
the expected result would be an estimated 1200 LCF. This number in itself may not appear unreasonable. However, using an estimate of 120 LCF per million person-rem population dose 14 , the population dose would have to be on the order of $1 \times 10^{7}$ person-rem to realize $1200 \mathrm{LCF}$. CRAC calculations show that the individual dose, as a function of distance from the point of release, falls below 0.1 rem within $2.5 \mathrm{~km}$. Therefore, one would have to conclude that the bulk of the $1 \times 10^{7}$ person-rem required by simple linear scaling is a result of hundreds of millions (to perhaps billions) of people receiving less than 0.1 rem over 40 years, a situation which is difficult to visualize considering that the total US population is on the order of 220 million.

The influence and importance of the population distribution is further illustrated by the data in Tables 4 and 5. Table 4 shows the population distributions used in the calculations reported in Table 5. These distributions essentially model various types of distributions from a large, densely-populated city down through cities and small towns to a rural area. Actual population densities from the Urban Study were used in one case. The results in Table $b$ have not been llusualized but reflcot the consequences (mean LCF) predicted using CRAC for the "baseline estimate release" from spent fuel as defined in the Urban study (See footnote on l'able 3). In lhe Urban Study it was observed that 80 percent of the LCFs occurred within 
$10 \mathrm{~km}$ of the release point for the hyper-urban population distribution (also see Figure 1). It is apparent from the data in Table 5 that a similar situation exists whenever distributions are used which model towns and cities. For Cases 2 through 6 the ratios of LCFs from one case to another approximate the population ratios close to the release point. Such scaling is not observed between the two uniform population cases: ( 7 and 8 , Tables 4 and 5 ) nor can one scale from the uniform to the distributed population. This behavior is attributed to several effects. In CRAC, the long term or chronic exposure calculation includes exposures from inhalation of resuspended material, groundshine from surface contamination and ingestion via food pathways. However, the model assumes that a given amount of land will only "feed" a fixed number of people regardless of the population density. Therefore, as the population density is increased to simulate cities, the exposure via the food pathway has less and less influence on the predicted consequences. For example, for one spent fuel release at 38.5 persons $/ \mathrm{km}^{2}$, the inqestion pathway accounts for 40 percent of the predicted LCF, but for the same release at 770 persons $/ \mathrm{km}^{2}$, the ingestion pathway accounts for only 3 percent of the LCF. Or stated another way, simply scaling from a few tens of persons per square kilometer to thousands per square kilometer implies that foodstuffs increase in the same proportion which is obviously unrealistic. However, scaling results for: small areas 
with high population densities is more accurate because the non-linear effect of the ingestion dose pathway has al ready been suppressed.

Another aspect of the influence of populalion distribution. is shown on Figure 1. The cumulative fraction of LCFs is shown as a function of distance from the release point for Case 1 and Case 7. (Table 4). It is noted that for a uniform population distribution the number of LCF continually increases, as would be experted, because even though the dose $1 \mathrm{~s}$ steadily declining as a function of the distance, the total number of people is increasing, the net result being significant additional LCF. In contrast, when there is a high population density close to the release point, the total number of LCF rises very rapidly and even the addition of more people at distances beyond about 15 kilometers doesn't add materialiy to the number of LCF predicted.

\section{Influcnoe of Thermal Content of Plume}

Pruyisions have been marie in CRAC for including thermal bouyancy in the released plume. This is required to adequately account for the sensible heat assuciated with potential reactor accidents, and for the much smaller eontribution from the radioactive decay of short-lived fission products. For small releases the provision of a thermal source may or may not be necessary. A portion of the Urban Study was concerned with the potential cunsequences 
from sabotage of shipping containers, especially spent fuel shipping casks, for which it was postulated that substantial quantities of high explosives would be involved. Based upon earlier work at Sandia, a value for the thermal source was selected. 15 Again, because CRAC results were being compared with METRAN results and because METRAN has no provision for buoyancy, a decision was made to explore the effect of the thermal source on consequence estimates. The results, shown in Table 6 , have been normalized to the values obtained with no heat in the release to better illustrate the behavior. The thermal content does have a strong effect upon the predicted early consequences for the "baseline estimate" release of the Urban Study. As heat is added to the release plume, the lofting reduces the expected doses close in and thus the associated EF and EM. This is as expected because the early consequences are threshold phenomena and because they are estimated on an individual dose basis. The estimate of LCF does not vary significantly with thermal content of the plume. Again this may be attributed to the total person-rem approach to predicting LCF.

\section{Conclusions and Recommendations}

Based upon the information presented here, the following conclusions may be drawn relative to using CRAC for small (compared to potential reactor accidents) atmospheric releases such as those postulated from sabotage of spent fuel in transit $(\sim 10,000 \mathrm{Ci})$. 
effects the major concern can be modelled with larger intervals.

2. Population distributions should be carefully chosen to match the situation being studied. If there - are strong variations in numbers depending upon direction, these should be included.

3. Consequence results should not be scaled from one population density to another.

4. The thermal content of the plume should be chosen to duplioate the experted condition as closely as possible. This is especially true for situations in which early effects to a close in population are being considered. 


\section{References}

1. Reactor Safety Study, NUREG-75/014 (WASH-1400), U.S. Nuclear Regulatory Commission, October 1975.

2. I. B. Wall, et al, Overview of the Reactor Safety study Consequence Model, NUREG-0340, U.S. Nuclear Regulatory Commission, 1977.

3. Reactor Safety Study Consequence Model CRAC, Computer Code Users Manual, available from Argonne Code Center, Argonne National Laboratory.

4. A. J. Russo, J. R. Wayland, L. T. Ritchie, Influence of Plume Rise on the Consequences of Radioactive Material Releases, SAND76-0534, Sandia Laboratories, Albuquerque, New Mexico, January 1977.

5. J. L. Sprung and H. W. Church, Effects of Wind Shear on the Consequence Model of the Reactor Safety study, NUREG-0175 (SAND76-0619), Sandia Laboratories, Albuquerque, New Mexico, January 1977.

6. L. T. Ritchie, W. D. Brown, J. R. Wayland, Effects of Rainstorms and Runoff on Consequences of Nuclear Reactor Accidents, SAND76-0429, Sandia Laboratories, Albuquerque, New Mexico, December 1976.

7. J. L. Sprung and H. W. Church, Sensitivity of the Reactor Safety Study Conseguence Model to Mixing Heights, NUREG0174 (SAND76-0618), Sandia Laboratories, Albuquerque, New Mexico, January 1977.

8. J. R. Wayland, Conditional Probability of Intense Rainfall producing High Ground Concentrations from Radioactive Plumes, NUREG-0209 (SAND76-0746), Sandia Laboratories, Albuquerque, New Mexico, March 1977.

9. J. L. Spruny, An Investigation of the Adequacy of the Composite Population Distributions Used in the Reactor Safety Study, SAND78-0556, Sandia Laboratories, Albuquerque, New Mexico, October 1978.

10. J. L. Sprung, G. P. Steck, A. W. Frazier, Correlations Between Wind Flow and Population Location at 67 Light water Nuclear Power Plant Sites, SAND78-05.57, Sandia Laboratories, Albuquerque, New Mexico, October 1978.

11. D. C. Aldrich, R. M. Blond, R. B. Jones, A Model of Public Evacuation for Atmospheric Releases, SAND78-0092, Sandia Laboratories, Albuquerque, New Mexico, 1978. 
12. C. V. Hodge and J. E. Campbel1, Calculations of Radiological Conseguences from Sabotage of Shipping Casks for spent Fuel and High Level Waste, NUREG-0194, U.S. Nuclear Regulatory Commission, February 1977.

13. N. C. Finley, et al, Transportation of Radionuclides in Urban Environs: Draft Environmental Assessment, NUREG/CR-0743 (SAND79-0369), Sandia Laboratories,. Albuquerque, New Mexico, September 1979.

14. The Effects on Populations of Exposure to Low-Levels of Ionizing Radiation, Report of the Advisory Committee on the Biological Effects of Ionizing Radiation, National Academy of Sciences, National Research Council, Washington, D.C., 1972 .

15. Personal Communication, H. W. Church to P. E. McGrath, Sandia Laboratories, Albuquerque, New Mexico, October 1978. 
Table 1

Normal Interval Radii for CRAC

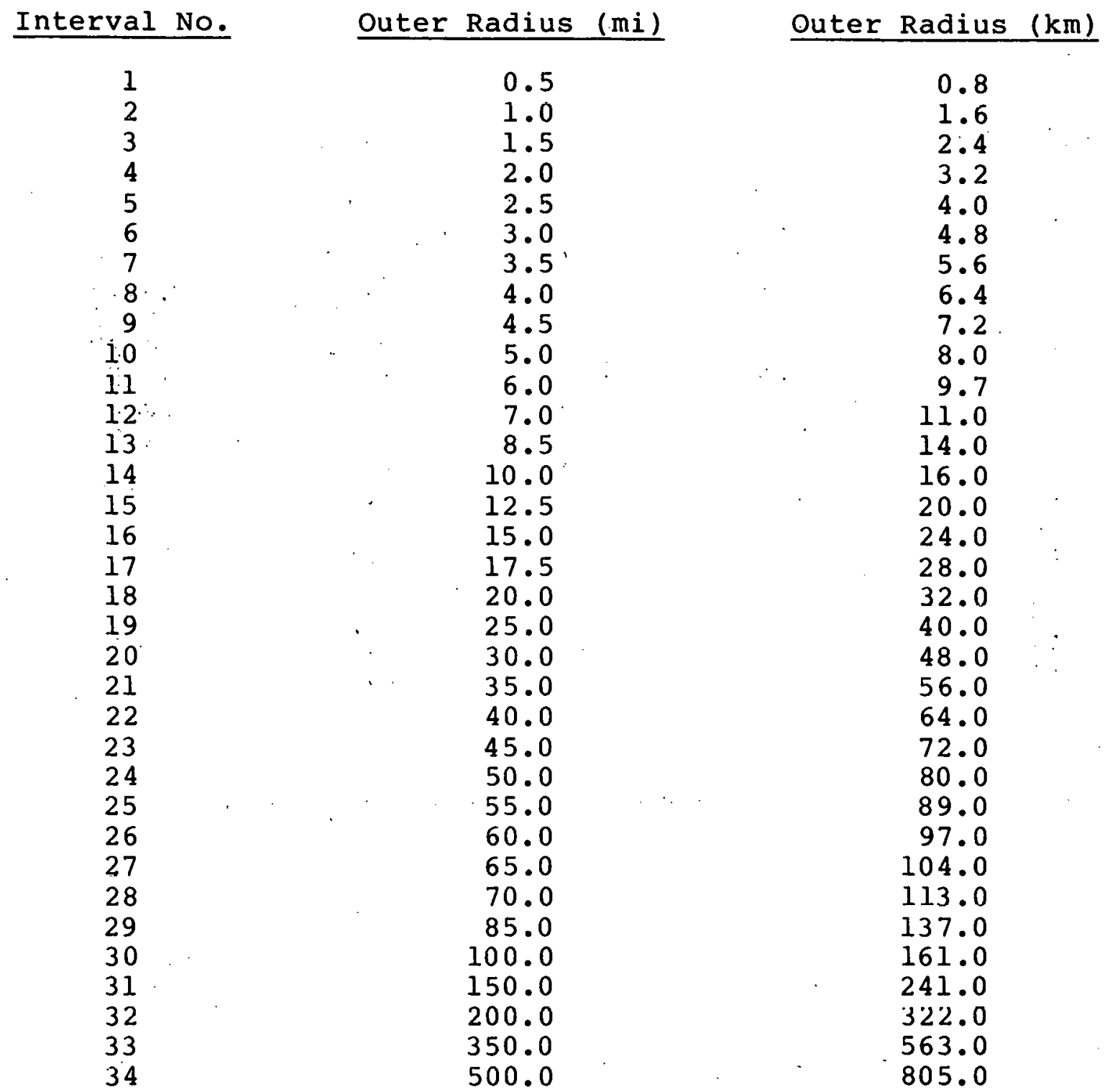


Table 2

Modified Close-in Interval Radii for CRAC Sensitivity Study

$\underline{\text { Radii Set }}$

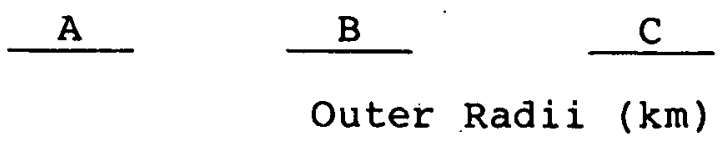

Interval No.

$\begin{array}{rrlll}1 & 0.5 & 0.25 & 0.12 & 0.06 \\ 2 & 1.0 & 0.5 & 0.25 & 0.12 \\ 3 & 1.5 & 0.75 & 0.38 & 0.19 \\ 4 & 2.0 & 1.0 & 0.5 & 0.26 \\ 5 & 2.5 & 1.35 & 0.63 & 0.32 \\ 6 & 3.0 & 1.5 & 0.76 & 0.37 \\ 7 & 3.5 & 2.0 & 1.0 & 0.5 \\ 8 & 4.0 & 2.5 & 1.2 & 0.8 \\ 9 & 4.5 & 3.5 & 1.7 & 1.2 \\ 10 & 5.0 & 4.4 & 2.2 & 1.6 \\ 11 & 5.5 & 5.4 & 2.8 & 2.4 \\ 12 & 6.0 & 6.4 & 3.2 & 3.2 \\ 13 & 7.0 & 7.3 & 3.6 & 3.6 \\ 14 & 7.5 & 8.5 & 7.2 & 7.2 \\ 15 & 11.2 & 11.2 & 11.2 & 11.2 \\ 16 & 16.0 & 16.0 & 16.0 & 16.0 \\ 17 \star & 28.0 & 28.0 & 28.0 & 28.0\end{array}$

*Beyond interval 17, all cases are the same as Normal, Table 1. 
Normalized Consequence Estimates from CRAC*

(Spatial Intervals Varied, Results Normalized to Those at $0.06 \mathrm{~km}$ Spacing) (Uniform Population Density $38.5 / \mathrm{km}^{2}$ ).

Nominal Interval

Spacing $(\mathrm{km})$
0.06
0.12
0.25
0.5
0.8
1.0

\section{Early Fatalities}

1.0

1.0

0.68

0.17

0

0

\section{Early Morbidities}

1.0

1.0

1.1

1.1

0.4

0
Latent

Cancer Fatalities

1.0

1.0

0.99

0.99

1.01

1.01

* Release was a mixed ¡ission product release from spent fuel, 1 percent of solids and 100 percent of noble gases from $1.4 \mathrm{MTHM}$ after $33000 \mathrm{MWD} / \mathrm{MT}$ at $40 \mathrm{kw} / \mathrm{kg}$, cooled 150 days. 
Table 4

Assumed Population Distributions for Consequence Estimates

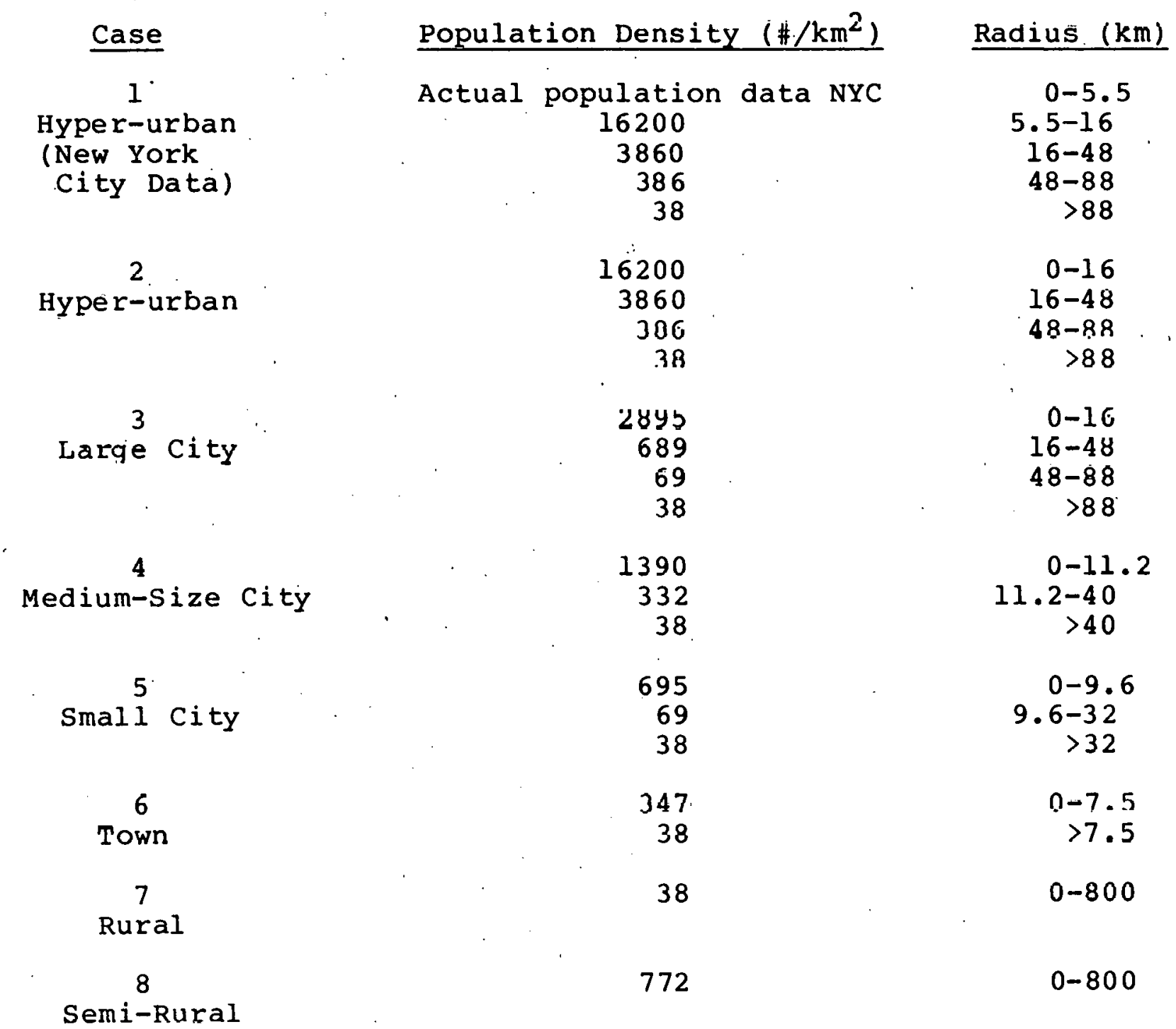


Table 5

Mean CRAC LCF Estimates for a Release from spent Fuel*

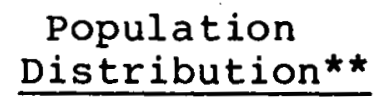

1

2

3

4

5

6

7

8

\author{
Latent Cancer \\ Fatalities
}

111

65

12

5.3

2.3

1.3

0.6

7.9

\footnotetext{
* Release was a mixed fission product release from spent fuel, 0.07 percent solids and 10 percent noble gases from $1.4 \mathrm{MTHM}$ after $33000 \mathrm{MWD} / \mathrm{MT}$ at $40 \mathrm{~kW} / \mathrm{kg}$, cooled 150 days.
}

**See Table 4 . 
Table 6

Normalized Mean Consequence Estimates for Releases from spent Fuel* with Varying Thermal Sources

Thermal Source

\begin{tabular}{cccc} 
(BTU/sec) & EF & EM & LCF \\
\hline 0 & 1.0 & 1.0 & 1.0 \\
$1.45 \times 10^{2}$ & 0.29 & 0.87 & 1.08 \\
$1.45 \times 10^{3}$ & 0.22 & 0.42 & 1.08 \\
$1.45 \times 10^{4}$ & 0.07 & 0.38 & 1.1 \\
$1.45 \times 10^{5}$ & 0.02 & 0.05 & 1.02
\end{tabular}

${ }^{\star}$ Release is described on Table 5 . 


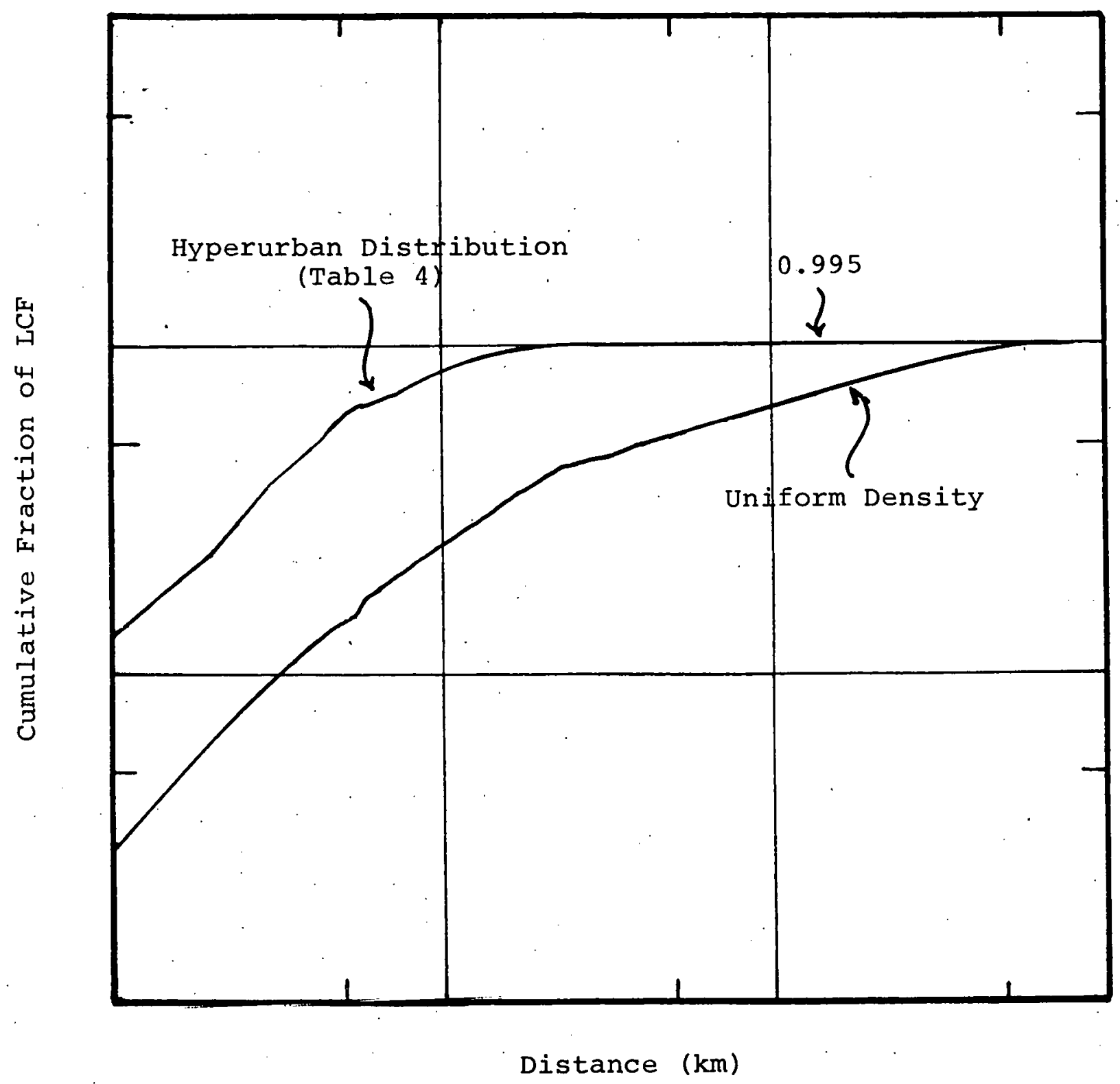

Figure 1. Cumulative Fraction of Latent Cancer Fatalities as Function of Distance from Release Point. 
Distribution:

U. S. Nuclear Regulatory Commission (5)

Office of Nuclear Regulatory Research

Probabilistic Analysis Staff

Washington, DC 20555

Attn: R. M. Blond

1233 J. M. Taylor

4000 A. W. Snyder

Attn: J. V. Walker, 4420

4410 D. J. McCloskey

Attn: J. W. Hickman, 4412

4413 N. R. Ortiz

L. D. Chapman, 4416

4413 L..T. Ritchie

4413 D. C. Aldrich

4413 N. C. Finley

4414 G. B. Varnado

4414 D. E. Bennett, III

4414 D. M. Ericson (10)

8266 E. A. Aas

3141 T. L. Werner (5)

3151 W. L. Garner (3)

For DOE/TIC (Unlimited Release)

$\mathrm{DOE} / \mathrm{TIC}$ (25)

(R. P. Campbell, 3154-3) 


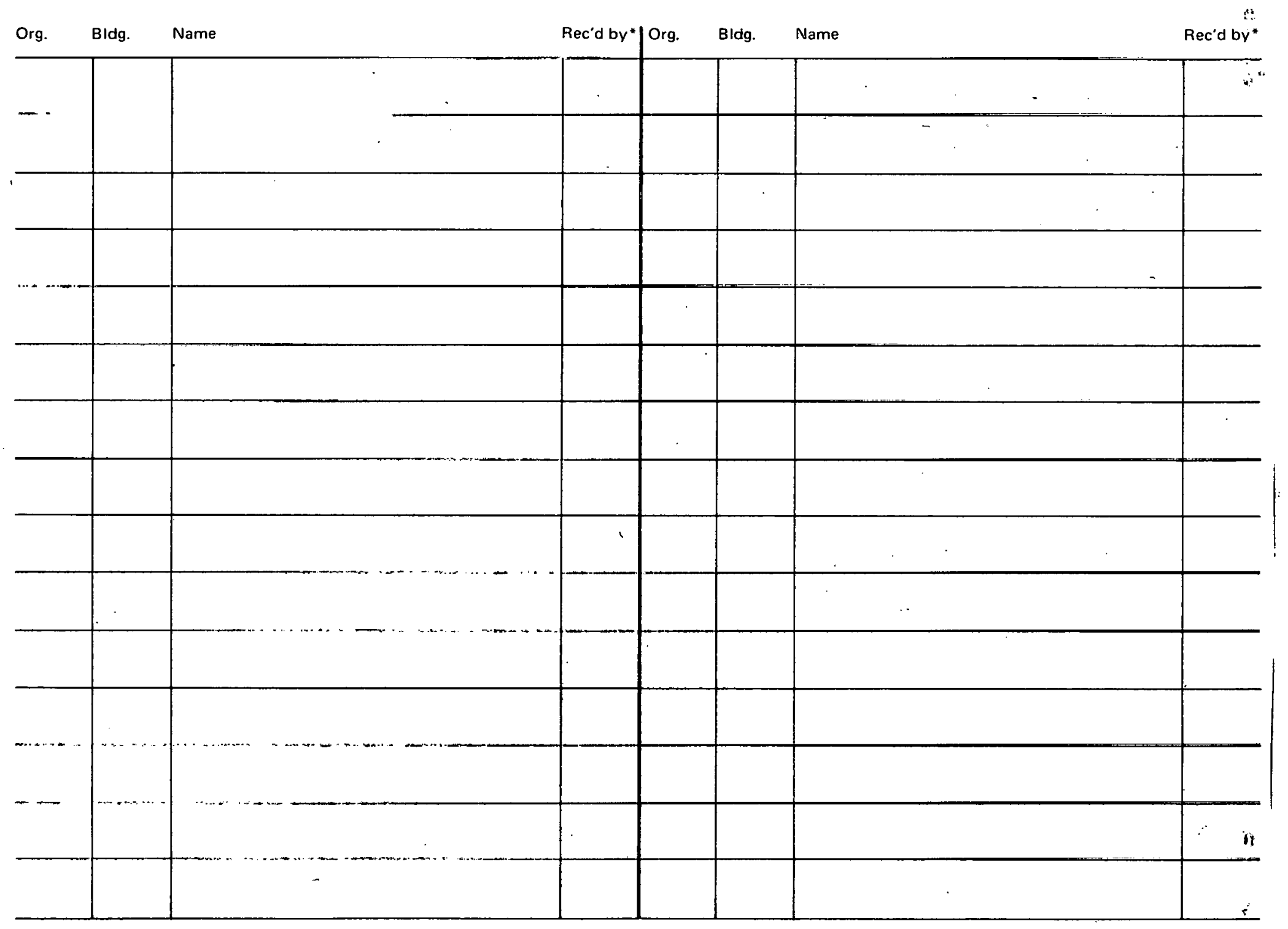

- Recipient must initial on classified documents. 